\title{
Barrett's Adenocarcinoma of the Esophagus
}

\author{
Better Outcomes Through New Methods of Diagnosis and Treatment
}

Angelika Behrens, Oliver Pech, Florian Graupe, Andrea May, Dietmar Lorenz, Christian Ell

\section{SUMMARY}

Background: Esophageal adenocarcinoma has attracted more attention among gastroenterologists recently because of its rapidly rising incidence in Western countries. Many new epidemiological findings have been published, and there have been numerous technical advances in diagnostic procedures and in multimodal treatment based on the staging of the disease.

Methods: In this paper, we selectively review the literature on esophageal adenocarcinoma, also considering the evidence-based recommendations contained in the guidelines of the German Society for Digestive and Metabolic Diseases (Deutsche Gesellschaft für Verdauungs- und Stoffwechselkrankheiten, DGVS) as well as the latest data from our own research team.

Results and conclusion: There have been major recent advances in the diagnosis and treatment of esophageal adenocarcinoma. New refinements in endoscopic techniques now make endoscopic treatment possible for early esophageal carcinoma. New surgical techniques and new strategies of neoadjuvant chemotherapy have lowered the morbidity and improved the outcome of patients with locally advanced disease. Molecular therapies, too, have shown promising initial results.

\section{Cite this as:}

Behrens A, Pech 0, Graupe F, May A, Lorenz D, Ell C: Barrett's adenocarcinoma of the esophagus-better outcomes through new methods of diagnosis and treatment. Dtsch Arztebl Int 2011; 108(18): 313-9. DOI: 10.3238/arztebl.2011.0313
Dr. Horst-Schmidt-Kliniken Wiesbaden, Innere Medizin 2 und Klinik Allgemein- und Viszeralchirurgie: Dr. A. Behrens, PD Dr. 0. Pech, Dr. F. Graupe, PD Dr. A. May, Prof. Dr. D. Lorenz, Prof. Dr. C. Ell erhaps no tumor in the past 10 years has undergone such changes in epidemiology, diagnosis, and treatment as adenocarcinoma of the esophagus (Barrett's carcinoma). The previous generation of textbooks gave it an extremely poor prognosis; now it has become an oncological disease that can be diagnosed at an early stage and treated with a high probability of cure.

The main contributor to this change has been the introduction of high-resolution video endoscopy and endosonography (endoscopic ultrasonography, EUS), which have made it possible to identify neoplasias early on, stage them accurately, and treat them.

Local endoscopic treatment of early Barrett's carcinoma (pT1m, L0, V0, G1/2) is now an established standard treatment in Germany (1). New operative techniques and neoadjuvant treatment approaches are reducing the morbidity and improving the prognosis of locally advanced tumors (2). Even in patients with metastatic disease, there is currently a great deal of promising data about the use of "small molecules," i.e., targeted therapy at the molecular level (3).

Generally valid, comprehensive guidelines for the treatment of esophageal carcinoma are still lacking. The German professional medical associations are called upon to create them.

The present article describes the current diagnostic standard and the various treatment strategies that follow on from this.

\section{Epidemiology and pathogenesis}

Esophageal carcinoma is still a rare tumor entity in Germany, with an incidence of 5000 new cases per year. However, in the past 30 years the incidence of adenocarcinoma of the esophagus has been rising more sharply than that of any other tumor in the western world (4). This trend is also visible in Germany, as documented for example by the Bavarian cancer registry for the Regensburg region, which shows a rise in adenocarcinomas as a percentage of esophageal carcinomas from $9 \%$ to $31 \%$ between 1992 and 2004. In the USA already more than $50 \%$ of malignant tumors of the esophagus are histologically adenocarcinomas, which have thus overtaken squamous cell carcinoma of the esophagus (which used to predominate) in frequency 


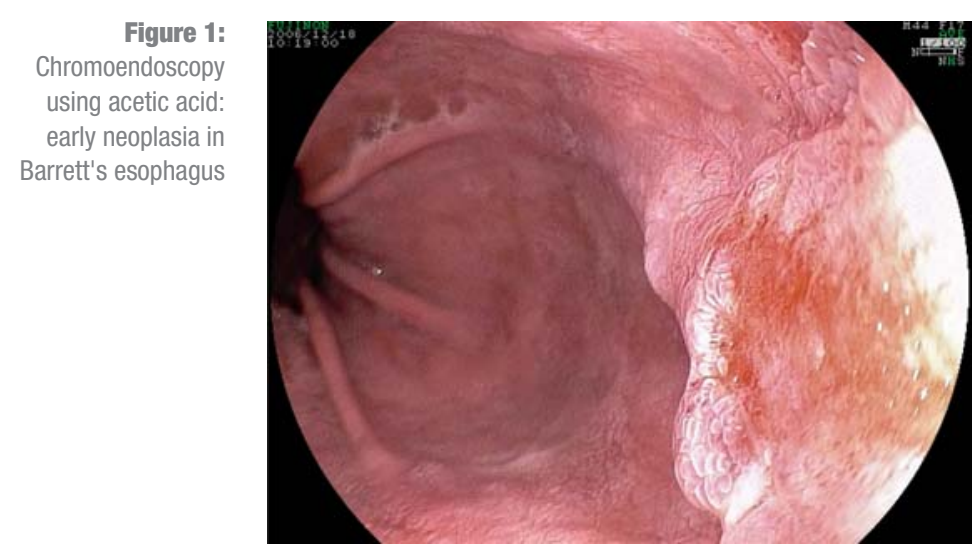

(5). In addition, there is a tendency to diagnose Barrett's carcinomas earlier, so that in some centers T1 tumors already account for more than $50 \%$ of the whole.

One thing that is certain is that gastric acid reflux, with heartburn as the main symptom, is the main risk factor for development of Barrett's carcinoma (6). Barrett's carcinoma development usually occurs over the course of years and involves a sequence of metaplasia-dysplasia (low-grade-high-grade neoplasia)-carcinoma leading to malignant differentiation (7). The lifelong carcinoma risk of a patient with Barrett's esophagus is not known, but a yearly carcinoma incidence of $0.5 \%$ per year may be assumed, which would mean that $5 \%$ of patients with Barrett's esophagus would develop carcinoma within 10 years (8). In future, the ability to perform individualized risk stratification using genetic markers would be desirable.

There is consensus that male sex constitutes a risk factor ( $\mathrm{m}: \mathrm{f}=7: 1$ ) for developing adenocarcinoma of the esophagus. In addition, familial increased incidence of Barrett's esophagus and Barrett's adenocarcinoma has been observed (9).

One more definitely established association is that between Barrett's adenocarcinoma and overweight, especially abdominal obesity (10).

The combination of overweight and reflux symptoms is associated with a higher risk. Nicotine abuse, on the other hand, plays only a subordinate role in the pathogenesis of esophageal carcinoma, and alcohol consumption no notable role (11).

\section{Clinical features}

Locally circumscribed tumors (T1/T2) cause no tumorrelated symptoms. Rarely they become manifest by gastrointestinal bleeding in patients with an existing ulcer. However, the underlying reflux disease causes the typical symptoms of heartburn, epigastric sensation of pressure, or retrosternal pain in about half the patients, and should prompt referral for index endoscopy. Locally advanced or metastatic tumors are characterized clinically by dysphagia or, less frequently, with anemia and bleeding, weight loss, or loss of appetite.

\section{Diagnosis and staging \\ Endoscopy}

Examination using high-definition video endoscopy is the primary and central diagnostic technique. Additional techniques such as real chromoendoscopy (e.g., with dilute acetic acid), and virtual chromoendoscopy - neither of which is evidence-based as yet - are intended to enable diagnosis of early neoplasias at the millimeter level by improving the visualization of surface structures (Figure 1). The value of these procedures is currently under investigation. Histological confirmation by biopsy remains the standard. The use of so-called endomicroscopy (microscopic evaluation in vivo) is purely experimental at the present time.

The depth of wall infiltration by the tumor and the para-esophageal lymph nodes are evaluated by EUS, which is superior to other imaging techniques for this purpose (12). Complementary procedures such as elastography or contrast EUS are still at the development stage. Should EUS raise suspicion of local lymph node metastasis in a patient with a T1 or T2 tumor, the diagnosis should be confirmed histologically/cytologically by means of EUS-guided fine-needle aspiration, since proof of lymphatic tumor involvement would change the treatment strategy.

\section{Other imaging procedures}

The diagnostic work-up should include multiple-array thoracic computed tomography (CT) including the upper abdomen, and abdominal ultrasonography. Neither magnetic resonance imaging (MRI) nor positron emission tomography (PET) or PET-CT imaging has been shown at present to be adequate as standard investigations in Barrett's adenocarcinoma.

\section{Treatment \\ Curative endoscopic resection}

If endoscopy shows a T1 tumor, the guidelines of the German Association for Digestive and Metabolic Diseases (Deutsche Gesellschaft für Verdauungs- und Stoffwechselkrankheiten, DGVS) recommend performing a diagnostic endoscopic resection (evidence grade B). In this, the tumor-bearing mucosa including the submucosa beneath it is completely resected (Figure 2). If histological analysis of the resected sample shows a mucosal carcinoma without risk factors (no lymph node invasion, no venous infiltration by the tumor, R0 resection [basal margin]), the patient is considered treated with curative intent and requires regular endoscopic follow-up. In patients in whom submucosal infiltration and/or lymphatic or venous infiltration are shown, esophageal resection is recommended, since the expected rate of lymph node metastasization is $20 \%$ to $40 \%$.

Endoscopic resection in the esophagus is carried out using the "suck and cut" technique. This method has limitations particularly in regard to large-surface neoplasias, and for this reason a new endoscopic enbloc resection technique-endoscopic submucosal 


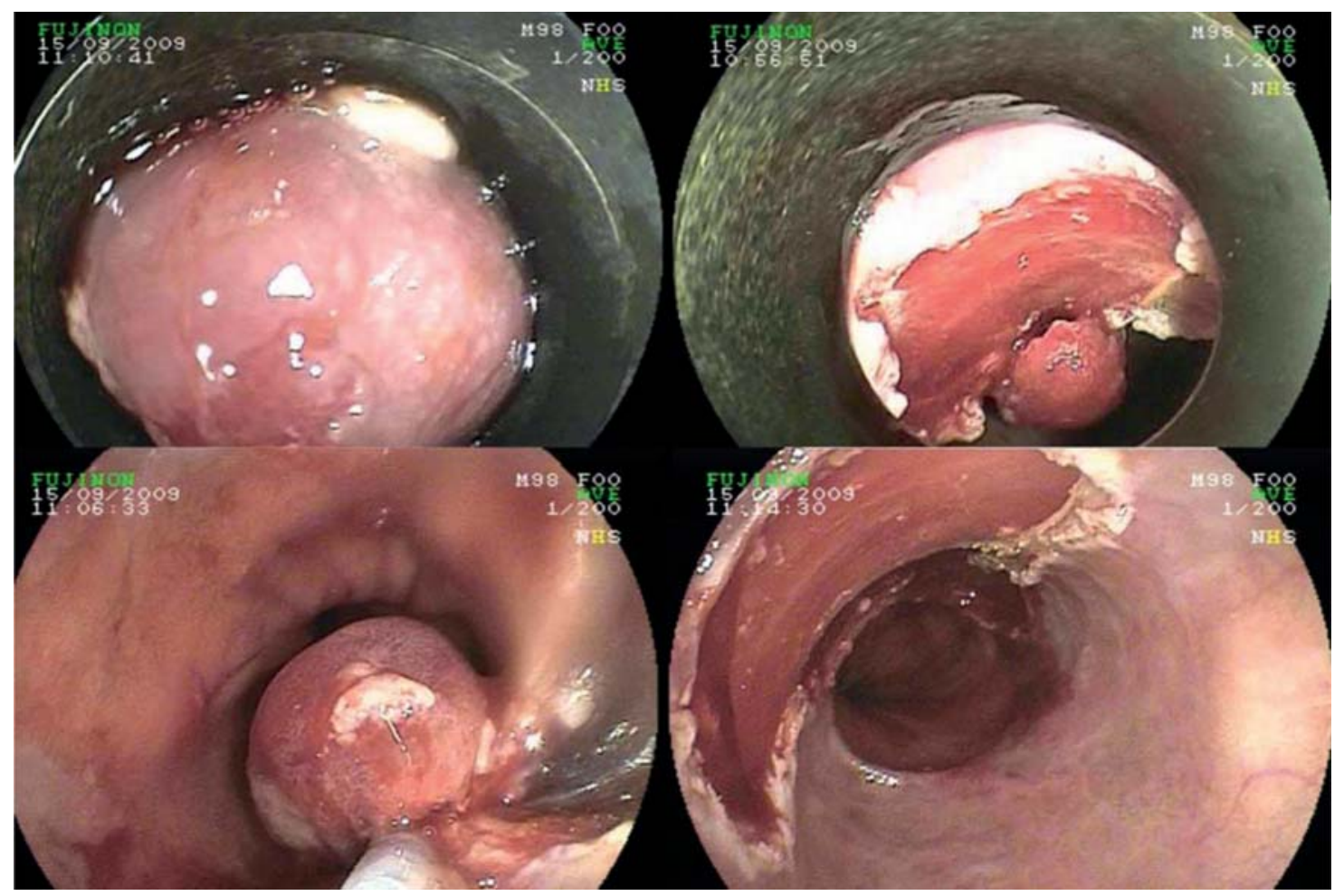

Figure 2:

Endoscopic four-field resection of a largesurface-area early Barrett's adenocarcinoma

dissection (ESD) - has been developed in Japan. This technique, however, makes high demands in terms of time, personnel, and equipment, is associated with more procedural risks, and has not yet become established in Europe $(13,14)$.

Thermal ablation techniques (such as argon plasma coagulation and radiofrequency ablation) are not primary treatment modalities for early Barrett's carcinoma, and neither is photodynamic therapy (licensed in the USA), because they make histological assessment of the tumor, and hence any risk assessment, impossible.

Endoscopic resection of mucosal early Barrett's adenocarcinoma without risk factors has developed into the therapy of choice, and is underpinned by a solid body of data: in the authors' center, which has experience of well over 1000 treated patients with early Barrett's carcinoma, morbidity is less than $5 \%$ and mortality is $0 \%$. Long-term survival corresponds to that seen in the comparable normal German population. After 10 years, $93 \%$ of patients are in complete remission (15-17). These data have been confirmed by other working groups, although their patient numbers are lower (17 to 28 patients) and their follow-ups shorter (12 to 19 months) (18-20). So far, no randomized, controlled study comparing operative therapy with endoscopic therapy has been carried out.

\section{Operative therapy}

While early Barrett's carcinomas in the mucosal stage (T1a) with few exceptions show no lymph node metastases, tumors that have invaded the esophageal wall more deeply (T1b to $\mathrm{T} 3$ ) require surgical resection.

The standard treatment consists of the classical abdominal-right thoracic esophageal resection with twofield lymphadenectomy and formation of a gastric tube and a high intrathoracic anastomosis. Even in surgical high-volume centers, this operation is associated with marked morbidity (30\% to 50\%) and considerable mortality ( $2 \%$ to $20 \%$ ) - the latter clearly being directly correlated to the number of patients operated on at the institution concerned $(21,22)$. In specialized centers, mortality must be expected to be below $5 \%$ (at the authors' center it is $3.2 \%$ ).

Transhiatal esophageal resection shows lower morbidity and mortality than the classic two-field procedure. This advantage is gained at the cost of less radical lymph node dissection and is associated with a slightly poorer-in patients with limited lymph node involvement even a significantly poorer-long-term survival (23).

Today esophageal resections are also carried out as combined thoracoscopic-laparoscopic procedures, although only a few centers do this in any volume of cases (24). One further technique is Merendino's modified, limited esophageal resection, in which resection of the gastroesophageal junction is combined with regional lymphadenectomy (celiac trunk and inferior mediastinum). For reconstruction, an approximately 12-cm-long section of jejunum is interposed. Because this technique, originally introduced in the 1950s as an 
FIGURE 3
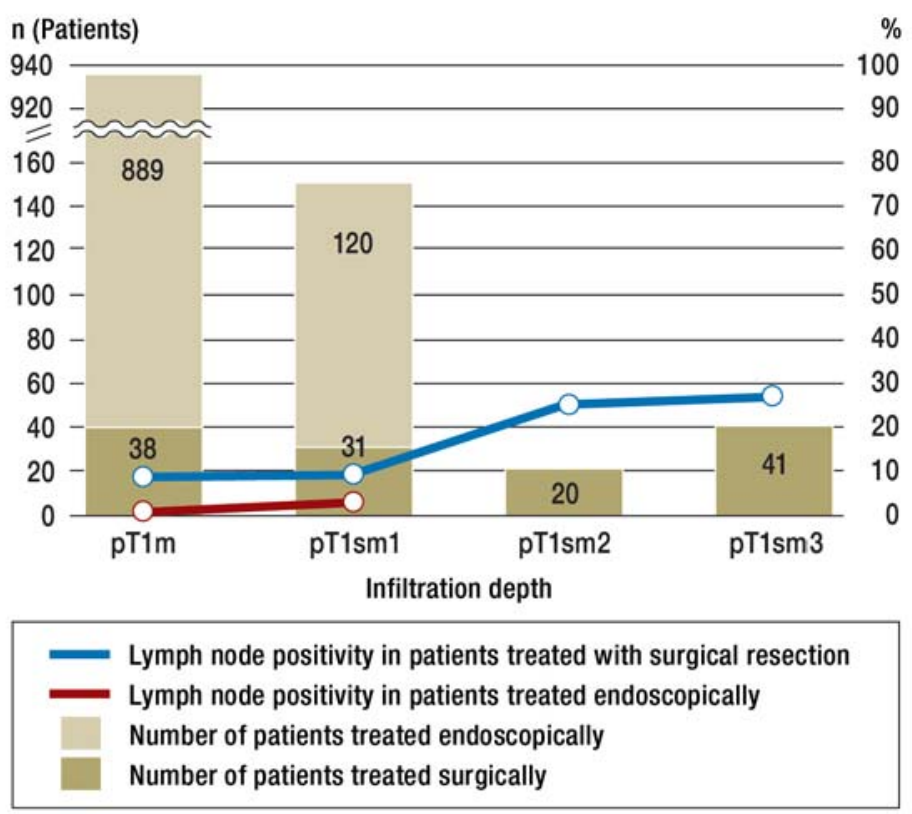

Histological stages and lymph node involvement in 130 patients with surgically treated early Barrett's carcinoma (June 2000 to June 2009, pT1m 7.8\%, pT1sm1 9.6\%, pT1sm2 25\%, pT1sm3 27\%) and lymph node positivity in 899 patients with endoscopically treated mucosal carcinomas $(0.34 \%)$ and 120 patients with sm 1 carcinomas $(2.5 \%)$

anti-reflux operation, allows only regional lymph node dissection and limits the scope for cranial extension of the resection, its indication is very narrowly defined, applying only to early carcinoma (T1) in short-segment Barrett's esophagus (25). The aim of the last two procedures mentioned, both of which are technically demanding, is to achieve lower postoperative morbidity, faster recovery, and a better quality of life for the patient. Not enough evidence-based data have been collected so far, so these procedures should only be undertaken within studies carried out at experienced centers.

Lymph node involvement, in Barrett's carcinoma as in other tumors, is the most important negative prognostic factor $(\mathrm{e} 1, \mathrm{e} 2)$. This is true even for early Barrett's carcinoma, as confirmed in the series of 130 surgically resected early Barrett's carcinomas studied by us. Once the tumor has infiltrated the second third of the submucosa (pT1sm2), the number of tumorpositive lymph nodes rises significantly (Figure 3) and the prognosis becomes significantly worse (Figure 4). At our center, if one adds together in stage T1m (mucosal carcinoma) and $\mathrm{T} 1 \mathrm{sm} 1$ (tumors infiltrating the first third of the submucosa) the patients who underwent purely endoscopic resection to those treated surgically during the same time period, the rates of patients with tumor-positive lymph nodes were $0.34 \%$ (pT1m: 3 out of 899 ) and $2.5 \%$ respectively (T1sm1: 3 out of 120 ).
Perioperative chemotherapy, combined radiochemotherapy

In patients with locally advanced tumors, perioperative chemotherapy should be the treatment of choice. The so-called MAGIC study, followed by the data of Boige et al., laid the foundation stone for carrying out perioperative chemotherapy in locally advanced tumors of the gastroesophageal junction and stomach $(2, \mathrm{e} 3)$. Both studies also showed a statistically significant survival advantage in the Barrett's carcinoma subgroup for multimodal treatment versus surgery alone. The five-year survival rates in the French group were 34\% (perioperative chemotherapy) versus 17\% (surgery alone).

The value of combined radiochemotherapy compared with chemotherapy alone is still not clear. Metaanalyses show an increased postoperative complication rate and increased mortality in patients who received combined pretreatment. In contrast to this, preoperative chemotherapy is not associated with increased toxicity (e4). Because of this difference, preoperative chemotherapy alone is the treatment of choice at many centers.

\section{Adjuvant therapy}

The data relating to adjuvant chemotherapy show no benefit after an $\mathrm{R} 0$ resection (e5-e7). The choice of therapy has to be made on a case-by-case basis, partly guided by the number of involved lymph nodes. This should be distinguished from adjuvant therapy (the postoperative part) as part of a perioperative chemotherapy plan.

Because of the lack of data, postoperative adjuvant radiation and radiochemotherapy are also therapies that are not established.

In patients with an $\mathrm{R} 1$ resection, postoperative radiation or combined radiochemotherapy may be considered. Because of the major operative trauma, the decision about the indication for treatment should be made with great caution and must take good account of the patient's postoperative general and nutritional status. In addition, this is another area in which no systematic data are available as a basis for decision making.

\section{Palliative treatment}

In patients with metastatic disease, or those for whom operative treatment cannot be considered because of co-morbidities, symptom reduction and hence usually improvement of dysphagia with restoration of the esophageal passage are the focus of therapy. This goal can be achieved by means of local endoscopic measures. The Box gives an overview of the treatment options. If the patient is in good physical condition, palliative chemotherapy should also be considered.

\section{Molecular targeting}

Molecular targeting is a modern therapeutic approach which employs antibodies or small molecules to inhibit tumor growth by altering signal transduction directly inside the tumor cell. 
At the 2010 American Oncology Meeting (American Society of Clinical Oncology, ASCO), a study was presented that, by analogy to breast cancer treatment, had investigated the value of giving trastuzumab to patients with advanced adenocarcinoma of the stomach and gastroesophageal junction (3). A statistically significant extension of survival was achieved in a defined subgroup. If this study finding is confirmed by other studies, it will represent a promising therapeutic approach that could also be introduced into perioperative therapy.

\section{Nutrition}

Optimization of nutrition is an important part of treatment, because patients are threatened by significant weight loss due not only to the catabolic tumor disease but also the dysphagia that often accompanies the tumor. The current state of care is inadequate on this point: only $30 \%$ of patients with at least a moderate risk of malnutrition actually receive adequate nutritional support (e8).

In the presence of a slight tumor stenosis, highcalorie liquid nutrition can be prescribed; in cases of severe dysphagia, however, placement of an enteral nutrition tube (percutaneous endoscopic gastro-/jejunostomy) must be considered. In our center, placement of a PEJ is standard before a planned gastric pull-up, in order to avoid adhesions due to a PEG in the area of the gastric wall. Data on the administration of immunemodulating nutritional solutions, such as solutions containing arginine, are unclear. If enteral nutrition is not possible, parenteral nutrition must be given.

\section{Prevention}

In medical drug treatment of symptomatic reflux disease, proton pump inhibitors (PPIs) are the most important class of substances for acid suppression; their role for the prevention of neoplastic development, however, is still under debate. It is unlikely that PPI therapy will lead to regression of Barrett's esophagus. The question of whether the metaplasia-dysplasia-carcinoma sequence can be prevented remains an open one (e9, e10).

One other approach in the area of medical prevention is to use cyclooxygenase-2 (COX-2) inhibitors or acetylsalicylic acid. COX-2 expression has been demonstrated in various human tumors. COX-2 stimulates proliferation of tumor cells and inhibits apoptosis. A protective effect has been shown in Barrett's carcinoma both for selective and for non-selective COX-2 inhibitors in vitro and in vivo (e11, e12). No outcome studies to show the value of COX-2 inhibitors and/or acetylsalicylic acid in preventing the development of Barrett's carcinomas have been carried out, and for this reason consumption of these substances cannot be recommended, particularly in view of their adverse effect profile.

The preventive effect of anti-reflux surgery for development of Barrett's neoplasia, propagated for many years, was not confirmed in two large controlled studies

\section{FIGURE 4}

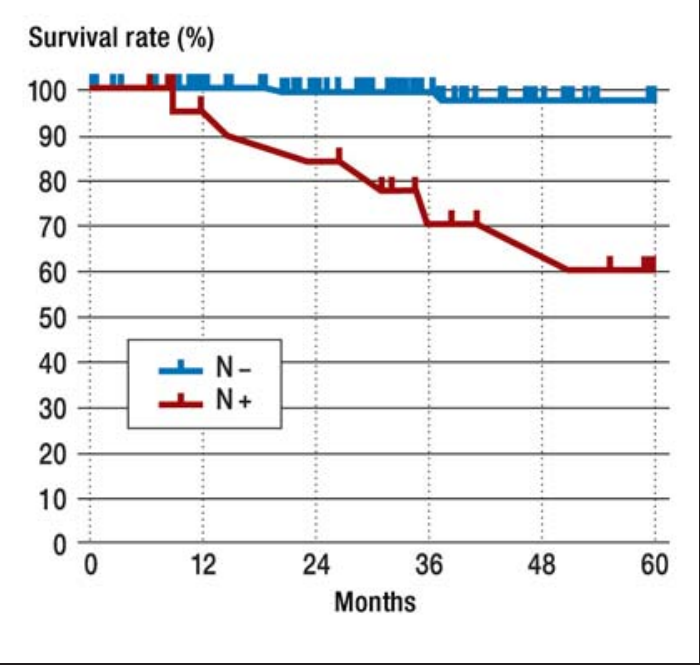

Overall survival (Kaplan-Meier) of surgically treated patients with early Barrett's carcinoma in relation to lymph node involvement $(n=130, p 0.001)$

\section{BOX}

\section{Palliative endoscopic measures for inoperable Barrett's carcinoma}

- Repeated endoscopic bougienage/dilation

- Argon plasma coagulation of exophytic tumor

- Implantation of a covered stent

- Brachytherapy 
and a meta-analysis (e13-e15). However, despite their large patient numbers, these studies had considerable limitations; in particular, the absence of prospective randomization and a strong patient selection bias weaken the power of these study results considerably.

Given the inadequate rate of complete ablations, the risks attached to ablative therapy, and the costs in relation to the low risk of transformation of Barrett's esophagus (e16), endoscopic preventive treatment in the form of thermal ablation of non-neoplastic Barrett's mucosa is not justified at present outside of clinical studies.

\section{Summary and future prospects}

- The incidence of esophageal adenocarcinoma has risen markedly in the past 10 years.

- The main mechanism of development of cancer is acid reflux.

- Local endoscopic therapy is an established curative therapy of mucosal Barrett's adenocarcinoma without risk factors (L0, V0, G1/2), which results in markedly lower morbidity and mortality than esophageal resection while giving a similar long-term survival (grade B recommendation).

- Patients with mucosal tumors with histological risk factors, submucosal tumors, and tumors in stage T2N0 should be advised to undergo primary esophageal resection at a high-volume center.

- Patients who present with a locally advanced tumor $(>\mathrm{T} 2)$ or a tumor with lymph node involvement $(\mathrm{N}+)$ should receive perioperative chemotherapy.

- Patients with metastatic disease may be offered palliative endoscopic treatment. Palliative chemotherapy may additionally be considered.

- All patients should receive specific nutritional advice and, if necessary, high-calorie nutritional support.

- New approaches to therapy in the area of molecular targeting, e.g., with trastuzumab, are promising and should continue to be investigated.

\section{Acknowledgments}

The authors wish expressly to thank the following for valuable support during their ongoing scientific and clinical collaboration: Prof. J. Pohl, Dr. M. Pauthner, Dr. H. Manner, Dr. J. Origer, Prof. M. Stolte, Dr. M. Vieth.

\section{Conflict of interest statement}

The authors declare that no conflict of interest exists according to the guidelines of the International Committee of Medical Journal Editors.

Manuscript received on 10 November 2009, revised version accepted on 11 May 2010

Translated from the original German by Kersti Wagstaff, MA.

\section{REFERENCES}

1. Leitlinie "Reflux"der DGVS 2005

2. Cunningham D, Allum WH, Stenning $S$, et al.: Perioperative chemotherapy versus surgery alone for resectable gastroesophageal cancer. NEJM 2006; 355: 11-20.

3. Bang YJ, Van Cutsem E, Feyereislova A, et al.: Trastuzumab in combination with chemotherapy versus chemotherapy alone for treatment of HER2-positive advanced gastric or gastro-oesophageal

\section{KEY MESSAGES}

- Every patient with known long-standing symptomatic reflux disease should undergo esophagogastroduodenoscopy at least once.

- High-resolution video endoscopy and endoscopic ultrasonography are the standard diagnostic procedures for the evaluation of the local finding of Barrett's carcinoma

- Endoscopic resection is the therapy of choice for mucosal Barrett's carcinoma without risk factors.

- Multimodal treatment approaches involving perioperative chemotherapy in addition to surgery are today standard for locally advanced Barrett's carcinoma stage $\mathrm{T} 3$ or $\mathrm{N}+$ or higher.

- Palliative treatment should be guided by symptoms.

junction cancer (ToGA): a phase 3, open-label, randomized controlled trial. Lancet 2010; 376(9742): 687-97.

4. Pohl $\mathrm{H}$, Welch HG: The role of overdiagnosis and reclassification in the marked increase of esophageal adenocarcinoma incidence. J Natl Cancer Inst 2005; 97: 142-6.

5. Brown LM, Devesa SS, Chow WH: Incidence of adenocarcinoma of the esophagus among white Americans by sex, stage, and age. J Natl Cancer Inst 2008; 100: 1184-7.

6. Lagergren J, Bergström R, Lindgren A, Nyrén 0: Symptomatic gastroesophageal reflux as a risk factor for esophageal adenocarcinoma. N Engl J Med 1999; 340: 825-31.

7. Spechler SJ: Barrett's esophagus. NEJM 2002; 346: 836-42.

8. Sharma P, Falk GW, Sampliner R, Spechler SJ, Wang K: Management of nondysplastic Barrett's esophagus: Where are we now? Am J Gastroenterol 2009; 104: 805-8.

9. Chak A, Falk G, Grady WM, et al.: Assessment of familiality, obesity, and other risk factors for early age of cancer diagnosis in adenocarcinomas of the esophagus and gastroesophageal junction. Am J Gastroenterol 2009; 104: 1913-21.

10. Hampel H, Abraham NS, El-Serag HB: Meta-analysis: obesity and the risk for gastroesophageal reflux disease and its complications. Ann Int Med 2005; 143: 199-211.

11. Wu A, Wan P, Bernstein L: A multiethnic population-based study of smoking, alcohol and body size and risk of adenocarcinomas of the stomach and esophagus (United States). Cancer Causes Control 2001; 12: 721-32.

12. Pech 0 , May $A$, Günter $E$, et al.: The impact of endoscopic ultrasound and computed tomography on the TNM staging of early cancer in Barrett's esophagus. Am J Gastroenterology 2006; 101: 2223-9.

13. Oka S, Tanaka S, Kaneko I, et al.: Advantage of endoscopic submucosal dissection compared with EMR for early gastric cancer. Gastrointest Endosc 2006; 64: 877-83.

14. Imagawa A, Okada H, Kawahara Y, et al.: Endoscopic submucosal dissection for early gastric cancer: results and degrees of technical difficulty as well as success. Endoscopy 2006; 38: 987-90.

15. Ell C, May A, Gossner L, Pech 0, et al.: Kurative endoskopische Therapie früher Adenokarzinome der Speiseröhre. Dtsch Arztebl 2003; 100: A1438. 
16. Pech 0 , Behrens $A$, May A, et al.: Long-term results and risk factor analysis for recurrence after curative endoscopic therapy in 349 patients with high-grade intraepithelial neoplasia and mucosal adenocarcinoma in Barrett's oesophagus. Gut 2008; 57: 1200-6.

17. Pech O, Manner H, May A, et al.: Endoscopic therapy in 1059 patients with high grade dysplasia and early adenocarcinoma in Barrett's esophagus - Lessons we have learned. Gastrointestinal Endoscopy 2009; 69: AB114-5.

18. Pacifico RJ, Wang KK, Wongkeesong LM, et al.: Combined endoscopic mucosal resection and photodynamic therapy versus esophagectomy for management of early adenocarcinoma in Barrett's esophagus. Clin Gastro Hepatol 2003; 1: 252-7.

19. Buttar NS, Wang KK, Lutzke LS, et al.: Combined endoscopic mucosal resection and photodynamic therapy for esophageal neoplasia within Barrett's esophagus. Gastrointestinal Endoscopy 2001; 54: 682-8.

20. Peters FP, Kara MA, Rosmolen WD, et al.: Endoscopic treatment of high-grade dysplasia and early stage cancer in Barrett's esophagus. Gastrointest Endosc 2005; 61: 506-14.

21. Birkmeyer JD, Siewers EA, Finlayson EVA, et al: Hospital volumen und surgical lethality in the United States. N Engl J Med 2002; 15: 1128-37.
22. Skipworth RJ, Parks RW, Stephens NA, et al.: The relationship between hospital volume and post-operative mortality rates for upper gastrointestinal cancer resections: Scotland 1982-2003. Eur J Surg Oncol 2010; 36: 141-7.

23. Omloo JM, Law SY, Launois B, et al.: Short and long-term advantages of transhiatal and transthoracic oesophageal cancer resection. Eur J Surg Oncol 2009; 35: 793-7.

24. Luketich JD, Alvelo-Rivera M, Buenaventura PO, et al.: Minimally invasive esophagectomy. Outcomes in 222 patients. Annals Surg 2003; 238: 486-95.

25. Stein HJ, Feith M, Mueller J, et al: Limited resection for early adenocarcinoma in Barrett's esophagus. Ann Surg 2000; 232: 733-42.

\section{Corresponding author}

Prof. Dr. Christian Ell

Dr. Horst-Schmidt-Kliniken, Wiesbaden

Ludwig-Erhard-Str. 100, 65199 Wiesbaden, Germany

For eReferences please refer to: www.aerzteblatt-international.de/ref1811 


\title{
Barrett's Adenocarcinoma of the Esophagus
}

\author{
Better Outcomes Through New Methods of Diagnosis and Treatment
}

\author{
Angelika Behrens, Oliver Pech, Florian Graupe, Andrea May, Dietmar Lorenz, Christian Ell
}

\section{eReferences}

e1. Westerterp M, Koppert L, Buskens CJ, et al.: Outcome of surgical treatment for early adenocarcinoma of the esophagus or gastro-esophageal junction. Virchows Arch 2005; 446: 497-504.

e2. Peyre CG, Hagen JA, DeMeester SR, et al.: The number of lymph nodes removed predicts survival in esophageal cancer: an international study on the impact of extent of surgical resection. Ann Surg 2008; 248: 549-56.

e3. Boige V, Pignon J, Saint-Aubert B, et al.: Final results of a randomized trial comparing preoperative 5 -fluorouracil(F)/cisplatin(P) to surgery alone in adenocarcinoma of stomach and lower esophagus(ASLE): FNLCC ACCORD07-FFCD 9703 trial. J Clin Oncol (Meeting Abstracts) 2007; 25(18): Suppl 4510.

e4. Gebski V, Burmeister B, Smithers BM, Foo K, Zalcberg J, Simes J; Australasian Gastro-Intestinal Trials Group: Survival benefits from neoadjuvante chemoradiotherapy or chemotherapy in oesophageal carcinoma: a meta-analysis. Lancet Oncol 2007; 8: 226-34.

e5. De Vita F, Giuliani F, Orditura M: Adjuvant chemotherapy with epirubicin, leucovorin, 5-fluorouracil and etoposide regimen in resected gastric cancer patients: a randomized phase III trial by the Gruppo Oncologico Meridionale (GOIM 9602 study). Ann Oncol 2007; 18: 1354-8.

e6. Cascinu S, Labianca R, Barone C, et al.: Adjuvant treatment of high-risk, radically resected gastric cancer patients with 5-fluorouracil, leucovorin, cisplatin, and epidoxorubicin in a randomized controlled trial. J Natl Cancer Inst 2007; 99: 601-7.

e7. Nitti D, Wils J, Dos Santos JG, et al.: Randomized phase III trials of adjuvant FAMTX or FEMTX compared with surgery alone in resected gastric cancer. A combined analysis of the EORTC Gl Group and the ICCG. Ann Oncol 2006; 17: 262-9.

e8. Odelli C, Burgess D, Bateman L, et al.: Nutrition support improves patient outcomes, treatment tolerance and admission characteristics in esophageal cancer. Clin Oncol 2005; 17: 639-45. e9. Feagins LA, Zhang HY, Hormi-Carver K, et al.: Acid has antiproliferative effects in nonoplastic Barrett's epithelial cells. Am J Gastroenterol 2007; 102: 10-20.

e10. Haigh CR, Attwood SE, Thompson DG, et al.: Gastrin induces proliferation in Barrett's metaplasia through activation of the CCK2 receptor. Gastroenterology 2003; 124: 615-25.

e11. Buttar NS, Wang KK, Anderson MA, et al.: Chemoprevention of esophageal adenocarcinoma by COX2-inhibitors in an animal model of Barrett's esophagus. Gastroenterology 2002; 122: 1101-12.

e12. Souza RF, Shewmake K, Beer DG, et al.: Selective inhibition of cyclooxygenase 2 suppresses growth and induces apoptosis in human esophageal adenocarcinoma cells. Cancer Res 2000; 60: 5767-72.

e13. Corey KE, Schmitz SM, Shaheen NJ: Does a surgical antireflux procedure decrease the incidence of esophageal adenocarcinoma in Barrett's esophagus? A meta-analysis. Am J Gastroenterol 2003; 98: 2390-4.

e14. Spechler SJ, Lee E, Almen D, et al.: Long-term outcome of medical and surgical therapies for gastroesophageal reflux disease: follow-up of a randomized controlled trial. JAMA 2001; 285: 2331-8.

e15. Ye W, Chow WH, Lagergren J, et al.: Risk of adenocarcinoma of the esophagus and gastric cancer in patients with gastroesophageal reflux disease and after antireflux surgery. Gastroenterology 2001; 121: 1286-93.

e16. Manner H, May A, Miehlke S, et al.: Ablation of nonneoplastic Barrett's mucosa using argon plasma, coagulation with concomitant esomeprazole therapy (APBANEX): a prospective multicenter evaluation. Am J Gastroenterol 2006; 101: 1762-9. 